\title{
PARA ALÉM DO BEM E DO MAL: UM NOVO MUNDO NOS TRÓPICOS*
}

Léa Freitas Perez**

Duas observações expressam o tom de minha fala. A primeira é de Tzvetan Todorov, quando ele refere preferir assumir abertamente sua visão das coisas sem a travestir em descrição das coisas elas mesmas. ${ }^{1}$ Ela faz eco às observações de Paul Veyne, segundo as quais "é mais importante ter idéias do que conhecer verdades", pois "ter idéias significa também dispor de uma tópica, tomar consciência do que existe, explicitá-lo, conceituá-lo, arrancá-lo à mesmice", mais ainda, "é deixar de ser inocente, e perceber que o que é poderia não ser", uma vez que "o real está envolto numa zona indefinida de compossíveis não-realizados; a verdade não é o mais elevado dos valores do conhecimento. ${ }^{2}$

No percurso que tenho seguido nos últimos anos minha intenção tem sido a de dialogar com o Brasil, de olhar diferentemente nosso país, de tentar responder de outro modo às questões que nos inquietam desde sempre. Dito de outro modo: tento mudar o registro analítico e fazer uma releitura da história a partir da reflexão sociológica, tomando como ponto de partida a crítica de certas verdades estabelecidas, tentando ultrapassar a oposição entre o intelectual e o sensível, típica da compartimentação

- Aula inaugural do Instituto de Filosofia e Ciências Humanas da PUCRS, proferida em 6-3-95.

** Professora do Departamento de Ciências Sociais e do Curso de Pós-Graduação em História do Instituto de Filosofia e Ciências Humanas da PUCRS.

1 TODOROV, Tzvetan. La conquête de l'Amérique. La question de l'autre. 1991. Paris, Seuil, p. 306.

2 VEYNE, Paul. O inventário das diferenças. História e Sociologia. 1983. São Paulo, Brasiliense, p. 54, 55. 
de origem positivista ainda preponderante nas chamadas ciências humanas. Realizo, assim, um exercício de reflexão e uma tomada de posição no que diz respeito às relaçōes da sociedade brasileira com a modernidade e, mais particularmente, no que diz respeito a uma certa concepção do Brasil para a qual, em nosso país, a modernidade é um projeto inacabado. Conforme já discuti em outra ocasião, segundo essa visão, o Brasil seria ainda incompleto, devendo se "modernizar" para "conquistar seu lugar no concerto das nações desenvolvidas". ${ }^{3}$ É o que a doxa chama de "dilemas brasileiros". O país seria ainda uma potencialidade - "o gigante adormecido", "o país do futuro" - e não uma realidade acabada. Um "país dual" formado por contrastes e por contradições. Os "dois Brasis", eterna e irremediavelmente divorciados, de costas um para o outro. Uma "sociedade a duas velocidades", cindida entre o moderno e o tradicional, entre a ordem e a desordem. Essa maneira de ver o Brasil articula-se em torno de uma lógica da falta e opera a partir de oposições binárias, sobretudo das oposições tradicional-moderno e centro-periferia. O centro - o moderno - é a vanguarda. Lá, tudo é criado - de forma original - por isso o seu poder de tudo comandar. A periferia - o tradicional - não passa de uma retarguarda. Aqui, tudo é cópia e, portanto, sem originalidade. A modernização, sinônimo de crescimento econômico segundo os padrões do centro, é o único caminho para a periferia sair da marginalidade e da dependência. $\mathrm{O}$ ponto focal da mudança é a industrialização que, bem implantada, agiria no conjunto da sociedade subdesenvolvida de maneira a aproximá-la das sociedades desenvolvidas, conforme uma visão messiânica de que o poder da economia resolve todos os problemas e uma lógica claramente evolucionista: os mesmos processos levariam ao mesmo fim. Essa concepção do Brasil e de seus dilemas de país dividido aponta para uma forma de tradicionalização do moderno. Vivemos uma sorte de nostalgia do que jamais existiu, segundo um raciocínio do tipo "se tivesse sido diferente" e de uma postura teórica míope, para a qual a persistência da tradição é, ao mesmo tempo, um sintoma e uma prova da execução apenas parcial do projeto moderno.

Ora, como a tradição que temos - independente de nossos desejos -é a da colonização portuguesa, é a ela que se deve atacar. Ah, se o Brasil tivesse sido colonizado pelos ingleses, tal como os Estados Unidos! Ah,

3 PEREZ, Léa Freitas. "Por uma poética do sincretismo tropical". 1992. In: Estudos Ibero-Americanos. Porto Alegre, PUCRS, 18(2): 43-52, dezembro. 
se o holandeses ou os franceses não tivessem sido expulsos! O Brasil seria hoje uma grande potência! Resumindo: a colonização portuguesa é a causa de todos os problemas - os ditos males e paradoxos do país. $\mathrm{O}$ raciocínio implícito é o seguinte: é preciso destruir completamente esse passado colonial que é uma mancha e um entrave à Ordem e ao Progresso e, em seu lugar, construir um país e uma sociedade "autenticamente nacionais" e "uma nova ordem em sintonia com o mundo contemporâneo". Em nome da modernidade redentora, uma série interminável de operações é posta em marcha com o objetivo de pôr em seu verdadeiro e legítimo lugar as coisas e os homens. Num tal campo de idéias, o trabalho social desenvolvido pela colonização lusitana é mal compreendido e malíssimamente analisado. Retém-se unicamente a dimensão colonizadora do processo, tomada num sentido negativo, mais ainda, pejorativo, esquecendo-se - evidentemente por um processo de hipostasia - de seu caráter de efetiva construção, pouco importando, nesse sentido, o objetivo visado.

Não se trata aqui de fazer uma apologia da empresa colonial, longe disso. Meu objetivo é simplesmente ver o Brasil português a partir de um olhar, ao mesmo tempo, mais objetivo e mais generoso. Para traçar um quadro global do trabalho social implicado na criação do Brasil e para situar o contraste entre a realidade inicial com que se depararam os colonizadores e o resultado obtido após três séculos de colonização proponho retomar alguns elementos.

Os portugueses encontraram terra e homens em "estado bruto": uma realidade onde tudo era - para eles - desequilíbrio, do excessivo e do lacunar. A terra, ao contrário do sonho de Caminha, era rebelde ao trabalho agrícola, com matagais de difícil aproveitamento e com rios quase impróprios à navegação. Nem ouro, nem seda. Os homens? Selvagens. Nos trópicos, aos olhos dos conquistadores, parecia faltar tanto a "riqueza organizada", quanto uma base para a atividade comercial tal como havia nas Índias.

Foi preciso preencher esse vazio absoluto. A promessa foi, para além do bem e do mal, cumprida. Seja como for, um mundo foi criado, uma sociedade complexa foi organizada. A América foi feita. Em torno de 1570, as bases do Brasil colonial estavam estabelecidas, a ordem

4 FREYRE, Gilberto. Casa grande e senzala. Formação da família brasileira sob o regime da economia patriarcal. 1984. Rio de Janeiro, José Olympio, 23. ed., p. 15, 24. Oliveira Vianna. Apud FREYRE Casa grande e senzala. Op. cit., p. 24. 
portuguesa inteiramente implantada. A sociedade organizada com a particularidade de ter sido forjada "menos pela ação oficial do que pelo braço e pela espada do particular". ${ }^{5} \mathrm{Na}$ base, a agricultura, a estabilidade dada pela família patriarcal e a regularidade do trabalho repousando na escravatura. Uma sociedade que se articulava em torno das grandes famílias e de suas casas. No comando, os potentados - senhores de terras e de escravos - "com altar e capelão dentro de casa e índios de arco e flecha ou negros armados de arcabuses às suas ordens". Homens independentes "que dos senados das Câmaras falaram sempre grosso aos representantes d'el Rei e pela voz liberal dos filhos padres ou doutores clamaram contra toda espécie de abuso da Metrópole e da própria Madre Igreja". 6

A colonização do Brasil foi uma obra de envergadura: empreendimento moderno que combinou ações comerciais e militares e cruzada civilizadora. A terra foi consolidada nas mãos portuguesas pela via da força armada, uma conquista militar. O próprio empreendimento ultramarino foi feito sob as graças papais, como uma cruzada moderna, cujas bulas reconheciam e aprovavam os primeiros passos. ${ }^{7}$ Em que pesem esses aspectos, a expansão portuguesa jamais implicou a aplicação de regras imperativas e rígidas. A coroa sempre soube ceder face às conveniências e às necessidades. O "realismo econômico" dos portugueses corrigiu, desde o começo, os excessos do espírito militar e religioso presentes na formação da sociedade colonial. ${ }^{8}$ Os acontecimentos pós 1530 são um bom exemplo.

A partir de 1530 ocorreu uma grande mudança nas relações entre a metrópole lusitana e a colônia tropical. O Brasil deixou de ser um mero empreendimento de exploração de produtos naturais para transformar-se em parte ativa da economia de reprodução em escala mundial como retaguarda agrícola de Portugal. A mudança foi ainda mais admirável se levarmos em conta que no começo a colonização foi feita, como observa Gilberto Freyre, "quase sem vontade, com um sobejo apenas de homens",

5 FREYRE. Casa grande e senzala. Op. cit., p. 4.

6 FREYRE. Casa grande e senzala. Op. cit., p. 4, 5.

7 Citando apenas dois exemplos: a bula Inter Coetera (1494) instituiu o patronato das terras conquistadas, colocadas sob a autoridade da Ordem de Cristo. Em 1551, pela bula Praeclara carissimi, a Ordem de Cristo é incorporada à Coroa de modo que o rei substituía o Santo-padre na administração religiosa dos territórios, percebendo os impostos correspondentes.

8 FREYRE. Casa grande e senzala. Op. cit., p. 8. 
o Brasil considerado "a Nazaré das colônias portuguesas", um vazio onde não havia nem ouro, nem prata, cedo encontrados pelos espanhóis no México, mas "somente pau-de-tinta e almas para Jesus Cristo."

Capitais e técnicas foram investidos na colônia a fim de criar um fluxo de bens destinado ao mercado europeu. Sob a pressão das circunstâncias, o colonizador português foi o primeiro a transformar a colonização tropical de pura extração de riquezas naturais em criação local de bens, cuja primeira expressão é a economia açucareira. ${ }^{10} \mathrm{O}$ sucesso do empreendimento é atestado, entre outros fatores, pelo fato de que em 1560 já havia, entre Porto Seguro e Pernambuco, 60 engenhos de açúcar em pleno funcionamento e de que a partir de 1570 o Brasil tornou-se o principal produtor mundial de açúcar. A colônia de plantação caracterizada pela base agrícola e pela fixação do colono na terra inaugurou uma nova fase na exploração colonial, dando origem à formação de uma sociedade singular.

A realização da colonização em um território tão imenso quanto vazio, como parecia ser o caso do Brasil, sobretudo para um empreendedor que, como era o caso de Portugal, dispunha de um pequeno contingente populacional, era um tarefa de peso. A solução mais razoável, diante desse quadro nada favorável, era alocar o grosso do trabalho nas mãos da iniciativa privada, responsável pelos gastos de instalação e pela defesa militar do empreendimento. As dificuldades, sabidas em grande número, seríam recompensadas através da concessão de privilégios relativos ao comando e à jurisdição das terras. Dessa maneira, a astuta metrópole criava um poderoso e atrativo elo entre possessão territorial e poder de mando, característica de base do sistema patriarcal brasileiro, cuja encarnação paradigmática é a figura do senhor de engenho.

Paralelamente à implantação da base econômica era preciso organizar o espaço. A coroa implantou o sistema de capitanias hereditárias (1532), segundo o modelo já utilizado nas ilhas Madeira, no arquipélago dos Açores, em Cabo Verde e em São Tomé. Fracassado o sistema das capitanias hereditárias, a metrópole introduziu um novo sistema administrativo, o Governo Geral (1549), tomando o êxito de São Vicente e Pernambuco como modelos. Uma tal reorganização administrativa mostra o sucesso da exploração econômica, em que pese o insucesso do

9 FREYRE. Casa grande e senzala. Op. cit., p. 242.

10 FREYRE. Casa grande e senzala. Op. cit., p. 17. 
sistema administrativo: "fracassaram as capitanias, mas prosperava a terra; malograva-se o sistema, mas vingava o negócio". ${ }^{11}$

Ao findar o século XVII, nova mudança de situação para o reino ibérico. Não tinha mais o monopólio do comércio do açúcar, nem das especiarias orientais. Pouco a pouco se tornava uma colônia inglesa. A queda do preço do açúcar devido à concorrência antilhana implicava graves problemas financeiros para a coroa. No Brasil, a economia açucareira encontrava-se desorganizada e a população dedicava-se unicamente a atividades de subsistência. Os colonos não podiam importar como faziam antes, pois exportavam pouco. O sistema estava em crise profunda; mas intervém o milagre: o ouro é descoberto, salvando todos. Uma vez mais a terra dos rios de mel mostrou sua generosidade. O paraíso sobre a terra tornou-se de novo factível. O ouro tudo mudou, mesmo que por um fugaz período.

A época gloriosa da colonização portuguesa teve fim no século XVIII. A mineração aurífera, geradora de grandes riquezas, após um período áureo entre 1740-1760, deixava de ser economicamente rentável. A colônia rica e poderosa exigia reformas e mudanças. Tanto em Portugal quanto no Brasil, desde o fim do século XVIII surgiram uma multiplicidade de reformadores e de projetos. A necessidade de reformar o sistema é consensual. O marquês de Pombal é a expressão mais desenvolvida da tendência modernizante que despontou na.metrópole. Sob a égide do pombalismo reformador, a metrópole tomou medidas que tendiam a uma certa modernização, como a liberação da implantação de manufaturas de ferros (1795) e mudanças no regime de exploração das minas (1803). Fato é, portanto, que desde cedo a questão da modernização foi posta em cena no Brasil. Uma modernização que significava, antes de mais nada, reformismo, sem pôr em causa a ordem estabelecida. Os ventos do contexto internacional impulsionavam ainda para mais longe. A independência dos Estados Unidos (1776) e o pensamento iluminista causaram forte impressão nos jovens brasileiros que estudavam na Europa. Emergiram algumas idéias de autonomia em relação metrópole, sendo a Inconfidência Mineira uma de suas manifestações.

Após 1792, de modo crescente, explodiram os conflitos estruturais do sistema colonial. O senhor de engenho e o grande fazendeiro brasileiros se viram submetidos às pressões de seus credores, os comerciantes

11 FAORO, Raymundo. Os Donos do Poder. Formação do patronato político brasileiro. 1989 , v. 1 e 2. Rio de Janeiro, Globo, 8. ed., p. 143. 
portugueses. Os mulatos, um grupo já importante da população, reclamavam sua exclusão social. O pequeno colono vivia com mais dificuldade a exploração dos grandes senhores. $\mathrm{O}$ comerciante não fazia senão seu trabalho quando exigia o pagamento das dívidas. $\mathrm{O}$ escravo queria a liberdade. Os brancos e os senhores, cônscios de sua "natural superioridade", aplicavam as regras estabelecidas "desde sempre". O açúcar já não era mais o centro da riqueza econômica. O ouro encontrava-se em queda livre. O café, apenas começava a aparecer. Em resumo: todas as partes do sistema tinham sua parte de razão e eram complementares. Diria que eram complementares por causa mesmo dos conflitos que os opunham. No Brasil, como observou judiciosamente Roger Bastide, "se a harmonia existe até no contraste, o contraste continua até a reconcilição dos antagonismos". ${ }^{12}$ Esta mistura de vozes nos coloca face a um universo plurivocal. ${ }^{13}$

No fim a criatura havia suplantado o criador. No começo do século XIX, a ordem colonial tinha seus dias contados. Em uma palavra: o paraíso mítico havia sido perdido pelo simples fato de que havia sido realizado, havia tomado forma e durava. ${ }^{14} \mathrm{Na}$ aventura, e a construção de um mundo novo nos trópicos o é, existe uma estreita relação entre o destino exterior e as fontes interiores da vida, de modo a produzir uma impressão de contraste, pois na aventura "a continuidade da vida é rejeitada por princípio, uma vez que pré-existe uma qualidade de estrangeiro, de intocável, de fora-de-série". Vale dizer que a aventura é independente de qualquer tipo de linearismo, de antes e de depois, ela determina seus próprios limites, ou seja, "a aventura não termina porque uma outra coisa começa, mas porque sua forma temporal, seu ato radical de terminar é exatamente a realização de seu sentido interior". ${ }^{15}$

Se a ação colonizadora portuguesa foi calcada na tradição, na continuidade, isso não impossibilitou alteraçóes de percurso quando necessárias. Mesmo que a maneira inicial de organizar a colônia tropical seguisse os mesmos princípios já testados na África e no Oriente, a

12 BASTIDE, Roger. Brésil. Terre des contrastes. 1957, Paris, Hachette, p. 13.

13 Um universo plurivocal é caracterizado pela pluralidade de vozes e de consciências eqüipolentes e distintas pela polifonia. Diferentes vozes cantam diferentemente um mesmo tema. BAKHTINE, Mikhail. La poétique de Dostoïevski. 1970. Paris, Editions du Seuil, p. 32, 33, 79.

14 ELIADE, Mircea. Le mythe de l'éternel retour. 1963. Paris, Gallimard, p. 134.

15 SIMMEL, Georg. Philosophie de la modernité. Tomme I. La femme, la ville, l'individualisme. 1989. Paris, Payot, p. 307, 308. 
conquista e o domínio de uma realidade nova, no caso do Brasil tão radicalmente diversa, foi uma situação que exigiu improvisação e adaptação. A política geral, as grandes direções de intenção foram acompanhadas de gestos particulares, relativos ao caso concreto. $\mathrm{O}$ ajustamento da regra global ao caso particular se impunha. A plasticidade e a flexibilidade tornaram-se obrigatórias. Não existia possibilidade para uma única via. A mistura era intrínseca, imperativa mesmo. A metrópole se adaptava às contingências, sabendo manter a tradição de continuidade onde era preciso, do mesmo modo que era capaz de introduzir inovações, como também misturar, com sucesso, o novo e o antigo. Da mistura, ou ainda melhor da mestiçagem, entre espírito de cruzada, exploração comercial e aventura, resultou um sistema social rico, que compõe um vasto campo para a análise sociológica.

Os eixos de compreensão do sistema colonial luso-brasileiro são, no plano econômico, a monocultura, o escravismo e a grande propriedade e, no plano sócio-cultural, o patriarcalismo. A monocultura associada ao escravismo nos deu um perfil de sociedade agrícola em termos de estrutura e de técnica de exploração econômica. Se a economia agrícola compunha a ossatura da sociedade colonial brasileira, sua carne era dada, sem a menor sombra de dúvida, pelo patriarcalismo. Se o patriarcalismo podia ser encontrado como possibilidade na ordem patrimonial portuguesa e, assim, nos princípios que nortearam a colonização dos trópicos, foi o meio local brasileiro que determinou seu florescimento. A autoridade pública, para além dos problemas provocados pelas distâncias entre a metrópole e a colônia, tinha que compor com o forte poder enraizado dos senhores de terra e de escravos; ela precisava contar com ele para poder agir no conjunto do território. ${ }^{16}$ Quem detinha efetivamente o poder, a autoridade e o prestígio era o grande proprietário; este, não o esqueçamos, observação aparentemente simples, mas freqüentemente esquecida nas análises sobre o período colonial, se, no começo, era um português, ou seja, um colonizador, em uma ou duas gerações - não mais - era um homem da terra, isto é, um brasileiro.

O produto sócio-econômico da ordem patriarcal brasileira foi a grande exploração agrícola, sob a forma do engenho de açúcar e da fazenda (criação de gado e de café), conduzida pela mão forte do todo

16 Dando apenas um exemplo das dificuldades de comunicação entre Portugal e sua colônia tropical: durante o século XIX, e com um bom navio à vela, eram necessários trinta e cinco dias para percorrer o trecho Lisboa-Bahia; no século XVI podia se prolongar até dois ou três meses. 
poderoso patriarca, senhor da vida e da morte de seus sujeitos - as mulheres, os agregados e os escravos. Colocado no centro da vida econômica e social da colônia, o grande proprietário tornava-se um aristocrata. Ele possuía tudo o que efetivamente importava possuir: o poder, a autoridade e a tradição, esta última ancorada na família.

O sistema de colonização deixava campo livre à ação individual: o colono fez-se no Brasil "senhor de terras mais vastas, dono de homens mais numerosos, que qualquer outro colonizador da América". ${ }^{17}$ Tanto em Portugal como no Brasil, a ascensão social através da prestação de "bons serviços" ao Estado sempre permitiu um amplo desenvolvimento das relações pessoais, centradas em laços de consentimento, de fidelidade, de simpatia e de obediência. Qualquer um podia tornar-se nobre. Em Portugal, dizia-se mesmo que todo mundo era nobre, se não de fato, ao menos de direito e, mais ainda, em modo de ser. A contrapartida da nobreza generalizada, que caracterizava o mundo colonial, era uma profunda aversão pelo trabalho ordinário, de onde a opção pelo escravismo - um dos centros do complexo colonial. Na mentalidade ibérica, o ideal em relação ao trabalho era uma digna ociosidade, uma vida de grande senhor, sem preocupações e sem o menor esforço. $\mathrm{O}$ que o português procurava não Brasil era a riqueza que custava audácia, mas jamais trabalho. ${ }^{18}$ Relembro, de passagem, uma referência a essa moralidade presente em nosso hino: o Brasil seria um país deitado eternamente em berço esplêndido. Certamente polêmica, de sentido dúbio, todavia reveladora, no plano sociológico, de uma certa maneira de ser e de se relacionar com o mundo que se afasta do paradigma burguês clássico do homem racional - trabalhador, disciplinado, organizado, poupador, etc. - e que se aproxima mais do modelo de homem da corte do século XVIII.

É moeda corrente dizer-se que a expansão portuguesa foi uma sucessão de ciclos: o desenvolvimento até o esgotamento de uma certa estrutura econômica centrada em torno de um único produto comercial. ${ }^{19}$ De acordo com essa lógica econômica, o Brasil teria sido concebido e

17 FREYRE. Casa grande e senzala. Op. cit., p. 190.

18 HOLANDA, Sérgio Buarque de. Raízes do Brasil. 1991. Rio de Janeiro, José Olympio, 22 ed., p. 18.

19 Os movimentos cíclicos sấo definidos como aqueles onde "a economia, no fim, retorna a seu ponto de partida". Assim, eles se opõem aos movimentos de longa duração, que "levam a mudanças estruturais". MAURO, Frédéric. Le Brésil du XV $V^{e}$ à la fin du XVIII siècle. 1977. Paris, Société d'Edition d'Enseignement Supérieur, p. 37 . 
organizado como uma empresa de exploração de produtos naturais: o pau-brasil, o açúcar, o ouro e o café. A economia brasileira teria se desenvolvido por saltos, isto é, por ciclos que se sucederiam uns aos outros, seja no tempo, seja no espaço e que teriam sempre nos levado da prosperidade à ruína. ${ }^{20}$ Não se poderia ver, para além desse olhar negativo da história, essencialmente moderno, uma outra concepção do tempo, da história e das relações com a natureza e com o espaço que guarda semelhanças com as chamadas sociedades tradicionais (não modernas)? Se não vejamos.

Nas concepções cíclicas do tempo e da história, a noção de retorno é uma maneira de anular a irreversibilidade do tempo. No tempo cíclico tudo recomeça em seu começo a cada instante. Nenhum acontecimento é irreversível e nenhuma transformação é definitiva. ${ }^{21}$

Não se pode negar que a concepção cíclica do tempo e da história, típica das sociedades tradicionais, manteve-se nas chamadas sociedades modernas, sobretudo até o século XVII. É somente a partir dessa época que, pouco a pouco, "o linearismo e a concepção progressiva da história se afirmam, instaurando a fé em um progresso infinito", até sua vulgarização no século XIX, com o triunfo das idéias evolucionistas. A economia política moderna, em sua versão evolucionista, reabilita as noções de ciclo, de flutuação, de oscilação periódica características das concepções tradicionais. É justo, pois, recolocar a questão, formulada por Mircea Eliade, se no fundo não seria somente nas teorias modernas que o sentido do mito arcaico da eterna repetição receberia todo seu alcance. ${ }^{22}$ A lógica luso-brasileira não seria solidária a um certo "caráter otimista da vida? A uma visão cuja idéia central é a de que nada é jamais completamente definido, que "tudo tem lugar de uma maneira cíclica, a morte é seguida inevitavelmente de uma ressureição, o cataclisma de uma nova criação"? O caráter otimista é marcado por uma consciência da normalidade da catástrofe cíclica, isto é, a certeza de que ela tem um sentido e sobretudo de que ela não é jamais definitiva. A regeneração necessariamente acontece. ${ }^{23}$ Uma perpétua renovação. Essa organização por ciclos não seria uma das particularidades da modernidade portuguesa?

20 Cf. PRADO JUNIOR, Caio. Formação do Brasil contemporâneo. Colônia. 1969. São Paulo, Brasiliense, 9. ed., p. 286.

21 ELIADE. Le mythe de l'éternel retour. Op. cit., p. 107.

22 ELIADE. Le mythe de l'éternel retour. Op. cit., p. 105, 161, 162, 164.

23 ELIADE. Le mythe de l'éternel retour. Op. cit., p. 106, 119, 152. 
A colonização do Brasil é solidária ao espírito de uma época plena de transformações, a um "tempo tão novo e com nenhum outro parecido". ${ }^{24} \mathrm{~A}$ ação colonial portuguesa é tributária da modernidade ocidental e de seu projeto civilizador. Todavia, ela foi orientada por uma ética da aventura e por uma concepção espaciosa e otimista do mundo, cujos principais elementos são a aspiração de obter sem custo tanto a prosperidade e a riqueza, quanto os títulos e as posições sociais privilegiadas, o que não é de ordem completamente moderna, no sentido de racional, impessoal, planificado, etc. ${ }^{25}$ Nas motivações que impulsionaram o pequeno reino lusitano em direção ao vasto oceano se faziam presentes, de modo ainda vivo, os sonhos dos cavalheiros do medievo. É justamente essa combinação entre tradição e modernidade que possibilitou a expansão colonial e a criação de um novo mundo nos trópicos.

$\mathrm{Na}$ lógica seguida por este trabalho nada permite pensar que as analogias que traço entre as sociedades portuguesa e brasileira baseiamse em uma perspectiva segundo a qual a origem condiciona o futuro. É justamente a crítica a esse tipo de olhar, típico da lógica da falta, que tento empreender. Meu objetivo é mostrar que, se quisermos melhor compreender esse mundo novo nos trópicos, é preciso levar em conta o realismo e o sonho, o velho e o novo, o espírito romântico e o espírito histórico, a mistura de elementos de organização social e de códigos de relação, num entrelaçamento particular de modernidade e de tradição. Repito aqui o que já disse antes, seguindo uma inspiração de Jean Baudrillard: paremos de procurar a "Revolução que não existe, a Grande Transformação que não tem sentido! No tombemos na armadilha dos "utópicos nostálgicos dilacerados pelo ideal, mas no fundo repugnando sua realização". ${ }^{26}$

24 Las casas Apud. TODOROV. La conquête de l'Amérique. Op. cit., p. 13.

25 Tomo de empréstimo a Sérgio Buarque de Holanda as idéias de ética da aventura e concepçāo espaciosa do mundo. HOLANDA. Raízes do Brasil. Op. cit., p. 13, 15, 16.

PEREZ. "Por uma poética do sincretismo tropical". Op. cit., p. 51. 